\title{
CRUZANDO LÍNEAS. TRAZANDO CONEXIONES
}

\author{
ELVIRA BURGOS DÍAZ \\ Universidad de Zaragoza
}

Recibido: $28 / 02 / 2010$

Aceptado: 13/04/2010

\section{Resumen}

Feminismo de la igualdad y feminismo de la diferencia pueden ser considerados marcos de intelección feminista. Ambos paradigmas siguen siendo pensados y ofrecen útiles producciones teóricas y prácticas. No son, sin embargo, los únicos caminos del feminismo contemporáneo. Emergen pensamientos y prácticas feministas que nos enseñan la potencia para el feminismo de un mirar con cuidado aquello que de cada teoría podamos aprovechar; aquello que nos pueda ayudar a continuar pensando y a seguir produciendo un saber y una acción feminista. Aquí argumentaremos a favor de feminismos que cruzan líneas, que trazan conexiones, que no buscan fundamentos sólidos, que cuestionan los fundamentalismos. Son feminismos cuya voluntad no es arrasar drásticamente con las categorías dadas sino que muestran su fuerza en la articulación profunda y compleja de unas con otras.

Palabras clave: igualdad, diferencia, libertad, sexo, género, deseo, heterosexualidad, lesbianismo, feminismo queer.

\begin{abstract}
Egalitarian/Humanist feminism and sexual difference feminism can be seen/understood as frames of feminist theorizing/ways of understanding feminism. Both paradigms are still fruitful and productive. However, they don't exhaust the possibilities developed in contemporary feminism/ these two trends are not the only paths explored in contemporary feminism. Styles of thought and practices have emerged to show us/expose/recover the aspects of those theories that are still useful; whatever can help us to go on/ keep thinking and producing/developing a body of feminist theory and practice. In this essay we argue for those feminisms that cross borders, draw connections, and call into question all kinds of fundamentalisms. Their goal is
\end{abstract}


not to destroy the old categories and foundations, but to articulate and combine them in complex and unexpected relations.

Keywords: egalitarianism/equality, difference, freedom, sexuality, gender, desire, heterosexuality, lesbianism, queer feminism. 
Aquello que sea el feminismo en una cultura dada requiere ser explicado. Decir que es pensamiento crítico y acción subversiva, en contra del sexismo, en defensa de ampliar afirmativamente las posibilidades de vida de las mujeres, es, sin duda, importante, mas no detiene la reflexión ante la pregunta por el feminismo. No es el feminismo un sistema teórico, tampoco un movimiento cerrado, compacto, unitario o inmóvil. Muchas y variadas son las perspectivas feministas que se han ido gestando y desarrollando en la cultura contemporánea, y tanto en un sentido teórico como en una dimensión práctica y política. Es sabido, suficientemente.

Ello no impide, no obstante, la formulación de marcos de intelección feminista que a modo de mapas sintéticos proporcionen un más fácil y rápido acceso a las tesis centrales y principales sostenidas por un conjunto de posiciones feministas. De ahí, sin agotar por supuesto la diversidad terminológica, las denominaciones de Feminismo de la igualdad y de Feminismo de la diferencia sexual, que, además, en nuestro contexto del Estado español son, quizá, todavía las más conocidas y usuales. Ambos paradigmas feministas continúan teniendo presencia, siguen siendo pensados y ofrecen útiles producciones teóricas y prácticas. Cierto. No son, sin embargo, los únicos caminos del feminismo contemporáneo; no agotan, ni mucho menos, la pluralidad del pensar y del hacer feminista.

Cabe reconocer el valor de estas líneas feministas, de la igualdad, de la diferencia sexual. Sus propuestas merecen seguir siendo consideradas, con atención, pues su vocación es la de transformar una sociedad que es todavía mayoritariamente patriarcal y masculinista. Afirmar esto no supone, por otro lado, que sea imprescindible y necesario aceptar en su totalidad un modelo feminista y rechazar el otro disciplinariamente. Florecen pensamientos y prácticas feministas que nos enseñan la potencia para el feminismo de un mirar con cuidado aquello que de cada teoría podamos aprovechar; aquello que nos pueda ayudar a continuar pensando y a seguir produciendo un saber y una acción feminista. Estos son feminismos que cruzan líneas, que trazan conexiones, que no buscan fundamentos sólidos, que cuestionan los fundamentalismos. Son feminismos cuya voluntad no es arrasar drásticamente con las categorías dadas sino que muestran su fuerza en la articulación profunda 
y compleja de unas con otras. Ante la urgencia del trabajo feminista más que desechar instrumentos emergen feminismos que los multiplican, que los anudan en clave multicolor, visibilizando su crucial interdependencia.

Una lectura cuidadosa, como así la merece el pensamiento feminista, además de lo dicho y una vez subrayada la presencia y utilidad inicial de los paradigmas feministas de la igualdad y de la diferencia sexual, nos conduce también a incidir en la complejidad interna que revela cada uno de esos horizontes feministas. Y esta es otra senda para una argumentación favorable a esa investigación feminista que no queda estancada sobre el suelo de categorías aisladas, atomizadas, binarias y dicotómicas, de cuyos efectos restrictivos y opresivos ya sabemos demasiado largamente.

Bajo el término feminismo de la igualdad se ha visto acogido un conjunto de reflexiones feministas que, nos planteamos, presentan postulados y afirmaciones que exceden los límites de un esquema estrictamente igualitarista, aunque, por otra parte, sea asimismo posible e incluso conveniente discutir el propio concepto de esquema igualitarista.

Indiscutiblemente, Simone de Beauvoir ocupa un lugar ejemplar en el panorama feminista del siglo XX y todavía en nuestros días. En una primera y muy generalizada lectura, su obra El segundo sexo vendría a defender y a potenciar un feminismo de la igualdad. Subraya cómo la situación de opresión que las mujeres padecen en la cultura occidental no se sustenta en un hecho natural, o biológico, sino en el proceso de devenir mujer, orquestado e impuesto social, histórica y culturalmente.

Si acaso hay algo naturalmente dado es el sexo mientras que el género -dicho no tanto en el lenguaje propio de Beauvoir pero sí en el que su texto abre para la reflexión feminista-, lo que finalmente nos hace mujer u hombre, es un conjunto de apreciaciones de sentido instauradas histórica y culturalmente. Por lo tanto, lo anatómico, lo biológico, no es, en principio, lo determinante para la mujer o para el hombre. Es la interpretación cultural de esos rasgos físicos lo que establece los géneros, la separación de géneros y sus respectivos lugares en la sociedad. Los valores o disvalores adscritos a las mujeres no son pues naturales, no dependen directamente de su dotación física. De otro modo, el hecho de ser mujer no estaría necesitado de ningún movimiento del llegar a ser; ser mujer sería algo inmediato, directo, inmutable.

En la patriarcal cultura occidental, la mujer, interpreta lúcidamente Beauvoir, queda constreñida a ocupar el lugar de lo Otro, marginada en la opresiva posición de lo inesencial, de no sujeto, de objeto pasivo y sumiso, de cuerpo, solo cuerpo, atado y condenado a lo inmanente. Beauvoir denuncia hábilmente este entramado de injusticia donde entre mujer y hombre ni hay igualdad 
ni reciprocidad: el hombre se concibe a sí como sujeto autónomo, independiente, libre en su hacer que configura su ser; la mujer, a través de esta viciada relación de asimetría dialéctica, se concibe como «vasalla», como objeto no autónomo, como ser dependiente de la conciencia libre del hombre.

El legado feminista de Beauvoir implica que esta situación de opresión deberá quebrarse mediante el reconocimiento de mujeres y hombres como sujetos libres, autónomos, independientes. Y así concluye su obra aludiendo a que hay diferencias naturales entre mujeres y hombres pero que por encima de ellas se ha de afirmar, «sin equívocos», la «fraternidad $»^{1}$ entre unas y otros.

Un discurso igualitarista, en el sentido expuesto, está contenido en la obra de Beauvoir y en esta dirección ha sido abundantemente interpretada desde posiciones del feminismo de la igualdad.

Sin embargo, El segundo sexo ha sido motivo también para reivindicar otra óptica feminista cuyo centro de atención deja de ser el postulado de la igualdad. En el trabajo " ¿Qué es ser mujer? Butler y Beauvoir sobre los fundamentos de la diferencia sexual $»^{2}$, Sara Heinämaa discute la interpretación que encuentra en Beauvoir una teoría sobre el género, insistiendo en que en la obra beauvoiriana se desarrolla una descripción fenomenológica del complejo fenómeno de la diferencia sexual. De acuerdo con el análisis de Heinämaa, no solo no es lícito utilizar la distinción sexo-género para abordar el texto de Beauvoir sino que tampoco es adecuado el uso de la filosofía existencialista como clave de acceso. Desde el enfoque de Heinämaa resulta Beauvoir próxima, incluso, a la ética de la diferencia sexual de autoras como Luce Irigaray.

En todo caso, en El segundo sexo no está, para Heinämaa, a pesar de que reconoce la ambigüedad y dificultad del texto, la afirmación de que los procesos de socialización sean los determinantes del llegar a ser mujer por encima de los factores biológicos, como hormonas y cromosomas, y que en definitiva sean aquellos elementos socializadores la causa de la diferencia sexual. Las explicaciones causales del llegar a ser mujer, de tipo sociológico, y también las biológicas, psicoanalíticas y las basadas en el materialismo histórico, son, dice Heinämaa, rechazadas por Beauvoir para abrir paso a una exposición de la experiencia de ser mujer y de sus significados. El contexto de pensamiento adecuado, entonces, para entender la perspectiva de Beauvoir es, según Heinämaa, el de la fenomenología, en particular en la versión de Merleau-Ponty, donde se pone especial énfasis, diferenciándose de los dualismos cartesianos

1. De Beauvoir, Simone. El segundo sexo. Buenos Aires, Ediciones Siglo Veinte, 1987, segundo volumen, p. 518.

2. HAINÄMAA, Sara. "¿Qué es ser mujer? Butler y Beauvoir sobre los fundamentos de la diferencia sexual». Mora, n. ${ }^{\circ} 4$ (1998), pp. 27-44.

Feminismo/s 15, junio 2010, pp. 33-54 
y sartreanos, en pensar al sujeto de la experiencia no como conciencia aislada del mundo sino como cuerpo viviente que habita en relación con otros cuerpos.

Destacable del análisis de Heinämaa es, en todo caso y aunque no sea esta su meta, la puesta en evidencia de la dificultad, ambigüedad y contradicción de la narración de Beauvoir así como de la diversidad de interpretaciones, irreconciliables muchas de ellas, a que ha dado lugar. Dos paradigmas feministas divergentes han retomado El segundo sexo buscando ahí las huellas de sus propios postulados.

Partiendo en principio de Beauvoir, Monique Wittig nos encamina hacia un análisis feminista diferenciado. Ambas, Beauvoir y Wittig, coinciden en el rechazo de la noción esencialista de la feminidad. Así se constata, entre otras, en la obra de Wittig, cuya referencia a Beauvoir no deja lugar a dudas: «No se nace mujer» ${ }^{3}$. Más allá de Beauvoir, no obstante, Wittig cuestiona no solo la naturalidad del género sino también del sexo mismo. El sexo es una unidad ficticia, para Wittig. Sexo y género, las dos nociones, son resultado de elaboraciones socioculturales y lingüísticas.

$\mathrm{Ni}$ se nace mujer ni hay que llegar a serlo, según argumenta Wittig. Las mujeres no constituyen un «grupo natural»; están socialmente integradas en un grupo de carácter artificial que la cultura establece para someter tanto las mentes como los cuerpos de las mujeres. De este modo, Wittig persiste en denunciar el determinismo biológico porque a pesar de la obra de Beauvoir sigue perviviendo, y aun dentro del feminismo, la interpretación biologicista de la opresión de las mujeres.

La subordinación de las mujeres es un hecho social y para Wittig lo es también la división misma de lo humano en mujeres y hombres. Las críticas a la naturalización del sexo y a la imposición de la dualidad de sexos, son rasgos del feminismo de Wittig que no se hallan en Beauvoir. Tampoco encontramos en Beauvoir el valor determinante que otorga Wittig a la sexualidad. En la definición cultural de mujer encuentra Wittig una referencia fundamental a la sexualidad. Fuente de opresión es la sexualidad heterosexual que dicta la cultura encubriéndola bajo la categoría de naturaleza. Wittig relaciona directamente el pensamiento de la existencia de dos sexos y dos géneros con la imposición de la heterosexualidad. La afirmación de que hay dos sexos dados por naturaleza y de que la relación heterosexual es la legítima y natural es la que el texto «No se nace mujer» pone claramente en cuestión.

3. Wittig, Monique. «No se nace mujer». En M. Wittig, El pensamiento heterosexual y otros ensayos. Madrid, Editorial Egales, 2006, pp. 31-43. 
Este cuestionar el privilegio de la heterosexualidad es asimismo central en su texto «El pensamiento heterosexual» ${ }^{4}$. Es la normativa heterosexual, la cultura heterocentrada la que construye un diseño completo, de efectos opresivos, de toda actividad social e individual. La diferencia de los sexos forma parte de esta lógica de la heterosexualidad obligatoria, que va más allá del modo concreto de la práctica o relación sexual. De ahí que Wittig reclame el no llegar a ser mujer, el rechazo del término mujer, que para ella es una contundente marca de opresión que determina que esos individuos, denominados mujeres, se piensen a sí mismos y desarrollen sus vidas en relaciones de dependencia y de subordinación con respecto a los llamados hombres.

La figura de la lesbiana es la que Wittig propone como anuncio de la ruptura del contrato heterosexual; como camino posible para acceder a una vida en libertad. Wittig considera que de hecho, y no solo en un posible futuro, las lesbianas con sus prácticas están ya resquebrajando el orden heterosexual. Son un peligro para la pervivencia de la ley dominante. Sin duda, ese es el motivo por el que las lesbianas, nos cuenta Wittig, son tachadas «de no ser «verdaderas» mujeres» ${ }^{5}$, lo que indica que ser mujer no es una cuestión meramente natural, que para ser considerada como una mujer se exige asumir y representar con claridad un orden de valores culturales, el propio del «pensamiento heterosexual», aquel que establece la verdad o la mentira, el que se otorga la autoridad para decidir quién es y quién no es una verdadera mujer.

Esta es la conclusión de «El pensamiento heterosexual»:

¿Qué es la mujer? Pánico, zafarrancho general de la defensa activa. Francamente es un problema que no tienen las lesbianas, por un cambio de perspectiva, y sería impropio decir que las lesbianas viven, se asocian, hacen el amor con mujeres porque «la-mujer» no tiene sentido más que en los sistemas heterosexuales de pensamiento y en los sistemas económicos heterosexuales. Las lesbianas no son mujeres ${ }^{6}$.

El de Wittig es un feminismo que no solo no se sostiene en la categoría mujer como sujeto del feminismo sino que proclama el rechazo de la categoría misma, en cuanto marca de sexo y en cuanto marca de género, en ambos sentidos.

La estrategia social propia de la cultura heterosexual consiste en dotar de importancia y de valor a unas partes del cuerpo desestimando otras. En los

4. Wittig, Monique. «El pensamiento heterosexual». En M. Wittig, El pensamiento heterosexual y otros ensayos. Op. cit., pp. 45-57.

5. Wittig, Monique. «No se nace mujer». En M. Wittig, El pensamiento heterosexual y otros ensayos. Op. cit., p. 35.

6. WitTIG, Monique. «El pensamiento heterosexual». En M. Wittig, El pensamiento heterosexual y otros ensayos. Op. cit., p. 57.

Feminismo/s 15, junio 2010, pp. 33-54 
órganos de la reproducción parece residir el destino completo del individuo. De ahí la fuerza de la pregunta sobre si el bebé es niña o niño. Dualidad de sexos-géneros e imposición de la heterosexualidad son dictados sociales duramente cuestionados por el feminismo de Wittig, también, y con intensidad, en sus obras literarias. Contra la cultura heterosexual centrada en la genitalidad, el texto El cuerpo lesbiano ${ }^{7}$ nos aventura por el camino de una sexualidad no heterocentrada, no genitalizada; una sexualidad que erotiza el cuerpo en toda su extensión y pluralidad. Esta sexualidad es energía liberadora de las opresiones entrelazadas del sexismo y del heterosexismo. También en su obra Las guerrilleras ${ }^{8}$, la narración de Wittig pone en palabras una práctica feminista en libertad.

Un feminismo humanista, por una parte, se encuentra en la propuesta de Wittig. La lesbiana es su figura para designar un modo de ser y de vivir lo humano más allá o más acá del orden heterosexual que impone la dualidad de sexos y de géneros y que naturaliza también la relación asimétrica entre esas categorías, mujeres y hombres, artificialmente construidas.

Lo que dibuja Wittig es un camino feminista que ella cree capaz de trascender los sexos y los géneros dando acceso a la concepción de un sujeto humano unitario, igualitario, ni marcado por el sexo ni por el género; un sujeto humano que habría que pensar, en consecuencia, como previo e independiente, en alguna medida, a todo contexto social y cultural; un sujeto cuya libertad sería asimismo una dotación, en principio, presocial, y en este sentido no extraña el vínculo de Wittig con Beauvoir, ni que las dos pensadoras puedan verse acogidas por el feminismo de la igualdad.

Dada su crítica a la dualidad sexual y a la diferencia sexual, el feminismo de Wittig, por otra parte, se contrapone con claridad al feminismo de la diferencia sexual. Aunque Wittig reflexiona en sus textos, también y especialmente en los literarios, sobre cómo el género gramatical actúa para dar significado lingüístico a las personas y aunque afirma, en consecuencia, el poder del lenguaje para subordinar a las mujeres creando efectos de realidad, construyendo sus cuerpos, al tiempo que considera que el lenguaje puede trabajar además en un sentido inverso, en una dirección feminista; esta su atención al lenguaje no sigue la senda del feminismo de la diferencia sexual.

En el texto «La marca del género»" Wittig se propone destruir el género en el lenguaje o al menos modificarlo intensamente en su uso. Es en sus

7. Wittig, Monique. El cuerpo lesbiano. Valencia, Pre-Textos, 1977.

8. Wittig, Monique. Las guerrilleras. Barcelona, Seix Barral, 1971.

9. Wittig, Monique. «La marca del género». En M. Wittig, El pensamiento heterosexual y otros ensayos. Op. cit., pp. 103-116. 
obras literarias donde su peculiar empleo del lenguaje da cauce a su manifiesta intención de transformación lingüística. Las palabras, para Wittig, y no solo aquellas afectadas directamente por las marcas de género gramatical, sino todas las palabras, incluso las más alejadas de esas marcas de género, están comprometidas con el género, en sus formas, en sus significados. De lo que se trata, por consiguiente, es de provocar una alteración estructural en el lenguaje.

No se trata en Wittig de trabajar en favor de la feminización del mundo ni de defender la existencia y el valor feminista liberador de una supuesta escritura, literatura femenina, como así lo hicieran Hélène Cixous o Luce Irigaray, autoras centrales del pensamiento francés de la diferencia sexual. Apostar por una escritura femenina sería para Wittig defender justo aquello contra lo que su pensamiento y su texto se dirige, esto es, la existencia de una humanidad diferenciada social y políticamente en sexos dicotómicos y marcada en el lenguaje por el género gramatical. La expresión «escritura femenina» permanece atrapada en el universo cultural masculino dominante.

La lengua permite, según Wittig, que la escritura pueda ser un espacio de libertad, pero se trata de una escritura en la que la convención de los sexos no sea determinante, donde se dé la posibilidad de construir la idea de un neutro vencedor de la diferencia sexual. Para aquellas defensoras de la diferencia sexual, es la lengua materna, la voz de la madre, la que debe ser buscada y rememorada como vía de encuentro con la feminidad y como camino para dar presencia a un simbólico femenino. Wittig, por el contrario, alude en el texto que escribe en colaboración con Sande Zeig, Borrador para un diccionario de las amantes ${ }^{10}$, a que la «madre», entendiendo que ese término remite a la función biológica femenina, es la deformadora de la «lengua original», porque esa lengua perdida que las autoras fabulan como vehículo expresivo del ser unitario unido en lazo amatorio, ser recreado en la figura de las amantes amazonas, es lengua de unidad, de lo humano, y no la lengua del cuerpo y de la diferencia femenina. «Mujer», «mujeres», es una de esas palabras que por ser visibilizadora del género Wittig explícitamente rechaza.

En coherencia, ni la maternidad es un valor resaltado por Wittig ni admite las reivindicaciones de la superioridad biológica de las mujeres. Reclamar una superioridad biológica y la naturalidad de la maternidad es asentar la división sexual; es dotar del valor de lo natural a la opresión de las mujeres; es imposibilitar el impulso hacia la transformación social.

10. Wittig, Monique y Sande Zeig. Borrador para un diccionario de las amantes. Barcelona, Editorial Lumen, 1981.

Feminismo/s 15, junio 2010, pp. 33-54 
Bajo el feminismo de la diferencia sexual, está suficientemente mostrado, no se reconoce la propia Wittig. Con respecto a su vinculación al feminismo igualitario la cuestión es mucho más compleja. Tesis hay en su pensamiento que asumen postulados humanistas, como quedó dicho. Mas la centralidad que otorga a la sexualidad, su puesta en cuestión de la norma heterosexual entendiendo que esta norma es causa determinante de la opresión de las mujeres, su conceptualización del sexo, y de la dualidad de los sexos, como artificio construido e indistinguible, en consecuencia, de la acción de opresión que vehicula; esas consideraciones, en su articulación, distancian a Wittig del paradigma igualitarista.

La reivindicación de un feminismo lesbiano anida en Wittig. Nos aporta un «análisis lesbiano de la opresión de las mujeres» ${ }^{11}$, una dimensión que el feminismo, en muchos casos, desatiende. Cuando incorpora la perspectiva de la teoría lesbiana, el feminismo extiende y amplia su potencialidad crítica ${ }^{12}$. El feminismo ha de dejar de ser una reflexión heterocentrada y desde luego debe abandonar todo rasgo heterosexista, y para esta crucial tarea, inexcusable, las aportaciones de pensadoras como Wittig son inestimables. Sexo, género y sexualidad, son categorías culturales en las que se tejen nuestros cuerpos, nuestras emociones y pensamientos, nuestras vidas.

En una línea feminista sobre la que Wittig no pudo pronunciarse directamente dado que comenzó a emerger con posterioridad al tiempo de su obra, es en nuestros días recuperada como autora de lectura clave. La teoría queer, o, mejor, el feminismo queer -donde se piensan en interrelación sexo, género y sexualidad, cuanto menos-, incorpora como una de sus fuentes la desnaturalización del sexo de Wittig y su crítica a la heterosexualidad obligatoria, a la institución de la heterosexualidad.

Feminismo lesbiano y feminismo queer son, sin duda, modos de la reflexión feminista que evidencian la insuficiencia para el feminismo de la terminología igualdad y diferencia.

11. Wittig, Monique. «No se nace mujer». En M. Wittig, El pensamiento heterosexual y otros ensayos. Op. cit., p. 33.

12. Véase, SuÁREZ BRIONES, Beatriz. «De cómo la teoría lesbiana modificó a la teoría feminista (y viceversa)». En M. Bengoechea y M. Morales (editoras), (Trans)formaciones de las sexualidades y el género. Alcalá de Henares, Universidad de Alcalá. Servicio de Publicaciones, 2001, pp. 55-67. Véase también, SUÁREZ BRIONES, Beatriz. Sextualidades: teorías literarias feministas, Alcalá de Henares, Excelentísimo Ayuntamiento de Alcalá de Henares. Concejalía de la Mujer. Centro Asesor de la Mujer, 2002. Sobre feminismo lesbiano, véase además el texto de la misma autora «Desleal a la civilización: la teoría (literaria) feminista lesbiana». En X. M. Buxán (ed.), Conciencia de un singular deseo. Barcelona, Laertes, 1997, pp. 257-279. 
Influyente feminista lesbiana fue asimismo Adrienne Rich. Su conocido texto «Heterosexualidad obligatoria y existencia lesbiana», tampoco es posible encuadrarlo, sin violentarlo, ni en el feminismo de la igualdad ni en el de la diferencia sexual. Este escrito plantea desde el principio la necesidad para el feminismo de llevar a cabo una revisión profunda y crítica de la heterosexualidad, cuestión que es central para el feminismo lesbiano, y para el feminismo queer, y no así para los feminismos igualitarios y de la diferencia sexual. Escribe Rich en referencia a su texto: «No lo escribí para ensanchar divisiones, sino para animar a las feministas heterosexuales a analizar la heterosexualidad como institución política que arrebata el poder a las mujeres -y a cambiarla» ${ }^{13}$.

Y esta incitación de Rich a una crítica a la heterosexualidad, tanto desde los márgenes como desde su interior; a una decidida actitud de resistencia a los mecanismos de opresión, continúa estando plenamente vigente en nuestros días. Exigencia feminista que es imprescindible recordar una y otra vez, porque ya sea consciente o inconscientemente se olvida con frecuencia que la heterosexualidad no es, en principio y en contra de lo dicho por Simone de Beauvoir $^{14}$, una práctica sexual elegida en libertad sino una institución social obligada que afecta a las mujeres directamente al ser transmisora, reproductora, del sexismo. Las mujeres y feministas heterosexuales no deberían obviar que también ellas han de cuestionar la ley de la heterosexualidad puesto que sus vidas se desarrollan dentro de su carácter constrictivo. Rich afirma con contundencia que la institución de la heterosexualidad tiene que ver con la dominación masculina.

Clave para el feminismo es así rebatir la idea de que la heterosexualidad es innata en las mujeres que la habitan, y de igual modo la idea que a esta acompaña habitualmente: que la sexualidad es una cuestión privada que ni afecta de modo fundamental a la subjetividad ni a la vida pública y colectiva. Dicho de otro modo, el feminismo hace bien en reflexionar sobre la sexualidad

13. Rich, Adrienne. «Heterosexualidad obligatoria y existencia lesbiana». En A. Rich, Sangre, pan y poesía. Barcelona, Icaria, 2001, p. 41. El texto fue escrito inicialmente en 1978 y se publicó en 1980. En la nota 2, p. 43, Rich menciona que «La primera formulación que yo conozco de la heterosexualidad como institución apareció en la revista feminista lesbiana The Furies, fundada en 1971».

14. Para Simone de Beauvoir no hay una diferencia radical entre heterosexualidad y lesbianismo. Esto escribe, en relación a la sexualidad, en El segundo sexo. Op. cit., segundo volumen, p. 164: «En verdad, ningún factor es nunca determinante; siempre se trata de una elección efectuada en la entraña de un conjunto complejo, que descansa sobre una libre decisión; ningún destino sexual gobierna la vida del individuo, cuyo erotismo, por el contrario, traduce su actitud global con respecto a la existencia».

Feminismo/s 15, junio 2010, pp. 33-54 
puesto que hablar de sexualidad es hablar de placeres y deseos íntimos pero también hablar de normas, leyes y sanciones sociales. La sexualidad, en tal caso, no está ni mucho menos al margen de la práctica, individual y colectiva, del sexismo.

Género y sexualidad se entrelazan mutuamente. Con acierto nos interroga Rich sobre el porqué se considera necesario dar una explicación del lesbianismo mientras que no sucede igual con el deseo heterosexual. Permanece la creencia, que insistentemente debe ser desmantelada, de que lo natural, por razones biológicas, es la inclinación heterosexual del deseo. Imponer y mantener este supuesto no deja de ser un camino para garantizar el poder masculino, para garantizar a los hombres el acceso físico, emocional, económico a las mujeres. La cultura fuerza a las mujeres hacia la heterosexualidad. Por tanto, el feminismo no solo no debe tratar el lesbianismo como tema particular, contribuyendo así a la marginación e invisibilidad del amor entre mujeres; el feminismo tiene que plantearse revisar en profundidad la norma heterosexual.

El análisis de Rich extiende su fuerza, si cabe, cuando insiste en dirigir su llamada de atención crítica también hacia las feministas posicionadas en la heterosexualidad. Puede parecer lógico que mujeres a la vez lesbianas y feministas argumenten en contra de la institución de la heterosexualidad. Sus motivos son vitales, se aduce comúnmente. Mas asimismo afecta esta institución a las vidas de las mujeres heterosexuales, aunque, y lamentablemente, esta idea no sea fácilmente admitida. Rich quiere evidenciar, con lucidez y con acierto, cómo esta crítica, si bien es compleja y ardua para las mujeres heterosexuales, a ellas también les pertenece en tanto que los beneficios de tal crítica se extienden al conjunto de las mujeres:

Reconocer que, para las mujeres, la heterosexualidad puede no ser una «preferencia» en absoluto sino algo que ha tenido que ser impuesto, gestionado, organizado, propagado y mantenido a la fuerza, es un paso inmenso a dar si te consideras heterosexual «de forma innata» y libre (...) Para dar el paso de cuestionar la heterosexualidad como "preferencia» u «opción» para las mujeres -y llevar a cabo el trabajo intelectual y emocional subsiguiente- se requiere una clase especial de coraje en las feministas identificadas con la heterosexualidad, pero creo que las recompensas serán grandes: una liberación del pensamiento, el explorar nuevos caminos, el venirse abajo de otro gran silencio, una nueva claridad en las relaciones personales ${ }^{15}$.

Ser feminista es ya un acto de valentía. Más todavía si nuestra acción feminista se adentra en la problematización de la heterosexualidad. Un desgarro interno

15. Rich, Adrienne. «Heterosexualidad obligatoria y existencia lesbiana». Op. cit., pp. 65-66. 
es un sentir posible cuando desde el lugar de la vivencia heterosexual nos atrevemos con honestidad a someter a una incisiva revisión el orden cultural de la heterosexualidad. Este coraje del que habla Rich es, así lo considero con ella, prometedor.

Junto al concepto de heterosexualidad obligatoria, Rich aportó al feminismo el concepto de continuum lesbiano. Con existencia lesbiana se refiere a la «presencia histórica de las lesbianas» ${ }^{16}$. Continuum lesbiano encierra un conjunto mayor de significados que Rich quiere subrayar. Se trata de diferentes y diversas experiencias de mujeres identificadas con mujeres, intervenga o no el deseo sexual en este proceso de identificación, se reconozcan o no las mujeres como lesbianas. Vínculos y sentimientos de amistad compartida; energía, más o menos erotizada, que fluye de una mujer a otra; apoyos y cuidados mutuos; poder y autoridad que circula entre mujeres; sensibilidad femenina y hacia lo femenino; ejemplos son estos de lo queda albergado, sin agotar su significado, en el concepto de continuum lesbiano que funciona como instrumento de resistencia múltiple a la tiranía masculina y que incluye, aunque no necesariamente, el rechazo explícito de la heterosexualidad. El feminismo lesbiano de Rich expresa con el término continuum lesbiano la potencia que la identificación entre mujeres representa para la tarea de la liberación.

Continuum lesbiano es un nombre para denominar y para revindicar «una historia de resistencia femenina que no se ha entendido nunca completamente como tal porque ha estado fragmentada, mal nombrada, borrada ${ }^{17}$. Mostrar la fuerza de la identificación entre mujeres es el propósito de Rich. Alejado queda ello del mensaje igualitarista de Beauvoir que defiende la alianza entre mujeres y hombres. El valor que concede a la sororidad ${ }^{18}$ la acerca a ciertas posiciones del feminismo de la diferencia sexual; no, sin embargo, su lucha contra la heterosexualidad obligatoria, la centralidad que en su pensamiento tiene la sexualidad.

Sobre ello es esclarecedor recurrir al texto de la feminista de la diferencia sexual Rosi Braidotti. En su obra Sujetos nómades, afirma que la fuerza de lo femenino reivindicada por el feminismo de la diferencia sexual de Irigaray es comparable a la que sostiene la obra de Adrienne Rich ${ }^{19}$. Mas, si proseguimos la lectura de este escrito de Braidotti, hallamos un pasaje que nos muestra

16. Ibíd., p. 66.

17. Ibíd., p. 80.

18. Ibíd., p. 69.

19. BRAIDOTTI, Rosi. Sujetos nómades. Corporización y diferencia sexual en la teoría feminista contemporánea. Buenos Aires, Paidós, 2000, p. 157.

Feminismo/s 15, junio 2010, pp. 33-54 
con claridad una dimensión de la apuesta feminista de Irigaray que no es en absoluto compartida por Rich:

El texto de Irigaray se concentra en la política de la heterosexualidad radical; la autora sostiene que el misterio de la alteridad, de la relación con el otro y, especialmente, con el Otro que es el Ser Divino, se resume en el otro que es sexualmente diferente de uno, es decir, para cada sexo, el otro sexo (...) Y si bien las feministas se horrorizan ante lo que a primera vista parece un manifiesto a favor de las parejas heterosexuales monógamas, Irigaray se ha mostrado por completo inflexible, particularmente en su obra sobre las diosas mujeres y la experiencia femenina de lo divino, al afirmar que la política de la heterosexualidad radical como el tema subyacente del pensamiento de la diferencia sexual es un paso necesario a fin de asegurar el surgimiento de la subjetividad femenina y de un sistema imaginario y simbólico que se adapte morfológicamente a la realidad corporal femenina ${ }^{20}$.

Feminista de brillante discurso, que asimismo, como Wittig, como Rich, somete a un severo examen la institución de la heterosexualidad, es Gayle Rubin. Su pensamiento también excede el marco dual de feminismo igualitariofeminismo de la diferencia. En su conocido escrito, de 1975, «El tráfico de mujeres: notas sobre la «economía política» del sexo» ${ }^{21}$, Rubin aporta a la teoría feminista la fórmula sistema de sexo/género con la que somete hábilmente a discusión las nociones naturalizadas de sexo, sexualidad, y, por tanto, la propia categoría mujer. La pregunta sobre el motivo por el cual la diferencia sexual supone una desigualdad social, Rubin la orientó hacia el análisis de las situaciones históricas y sociales concretas que se articulan en un contexto particular dado. El problema reside, a su juicio en el modo en que cada sociedad organiza las diferencias entre mujeres y hombres, en la determinación social del sexo, del género y de la sexualidad.

Las mujeres, las minorías sexuales y ciertos aspectos de la personalidad humana se encuentran en situación de opresión debido a esa dimensión de la vida social que Rubin conceptualizó como sistema de sexo/género y que describió así: «Como definición preliminar, un «sistema de sexo/género» es el conjunto de disposiciones por el que una sociedad transforma la sexualidad biológica en productos de la actividad humana, y en el cual se satisfacen esas necesidades humanas transformadas ${ }^{22}$. Y, además, afirmó:

20. Ibíd., p. 161. Braidotti se refiere aquí a la obra de Irigaray The Ethics of Sexual Difference.

21. RuBIN, Gayle. «El tráfico de mujeres: notas sobre la «economía política» del sexo». En M. Lamas (compiladora), El género: La construcción cultural de la diferencia sexual. México, Universidad Nacional Autónoma de México-PUEG, 2000, pp. 35-96.

22. Ibíd., p. 37. 
También toda sociedad tiene un sistema, de sexo-género -un conjunto de disposiciones por el cual la materia prima biológica del sexo y la procreación humanas son conformadas por la intervención humana y social y satisfechas en una forma convencional, por extrañas que sean algunas de las convenciones ${ }^{23}$.

Que haya algunas diferencias biológicas no lo niega Rubin pero su discurso pone el acento en que eso que denominamos sexo, lo supuestamente biológico del cuerpo, no se nos da de modo directo y neutro, como si fuera una ley inapelable y de obligado cumplimiento, sino mediatizado, contaminado culturalmente a través del género. El sexo se nos ofrece en una compleja articulación, sexo-género, que implica también a la sexualidad, y que conlleva que las desigualdades opresivas entre mujeres y hombres sean productos culturales y no desde luego necesidades naturales; tampoco se trata de universales culturales:

La división del trabajo por sexos, por lo tanto, puede ser vista como un «tabú»: un tabú contra la igualdad de hombres y mujeres, un tabú que divide los sexos en dos categorías mutuamente exclusivas, un tabú que exacerba las diferencias biológicas y así crea el género. La división del trabajo puede ser vista también como un tabú contra los arreglos sexuales distintos de los que contengan por lo menos un hombre y una mujer, imponiendo así el matrimonio heterosexual ${ }^{24}$.

Pensados en relación son el género, el sexo y la sexualidad, y en el interior del espacio de lo social y cultural donde ya no cabe seguir proclamando ni la pura naturalidad del sexo ni de la sexualidad. Sexo y sexualidad quedan desplazados por Rubin de lo meramente biológico hacia el lugar de lo sociocultural. Sexismo y heterosexismo, además, se alimentan mutuamente, trabajan en conjunto. Son modos de la actividad humana que en cuanto tal pueden ser cambiados mediante la lucha política. Y su texto se propone justamente eso: proporcionar un análisis que pueda ser usado como instrumento para la transformación social.

La causa de la opresión de las mujeres no es biológica ni se puede reducir al tráfico de mercancías, al modo de producción (como habían subrayado las tesis marxistas); reside en el tráfico de mujeres, en el sistema sexo/género que está implicado en la organización del parentesco. Por lo tanto, la opresión tiene una causa social, y ello es lo que quiere indicar Rubin con el concepto de «tráfico de mujeres», que muestra el control de la sexualidad femenina, su domesticación como producto de cambio, a través del intercambio de mujeres

23. Ibíd., p. 44.

24. Ibíd., p. 58.

Feminismo/s 15, junio 2010, pp. 33-54 
por parte de los hombres del grupo. De acuerdo con el estudio de Rubin, el acento del sometimiento de las mujeres, y de las «minorías sexuales», recae en la organización de la sexualidad como práctica heterosexual forzada que conlleva la imposibilidad de la autonomía para las mujeres y un rechazo del lesbianismo así como de otras prácticas sexuales alternativas. Sobre el lesbianismo en particular apunta la posibilidad de ser una válida y «sana $»^{25}$ estrategia de resistencia a la opresión.

El proyecto feminista de Rubin anuncia explícitamente la urgencia de llevar a cabo una revolución de la heterosexualidad normativa, lo que implica una revolución del parentesco, que supondría a la vez un cuestionamiento severo de los géneros normativos. El tabú del incesto en particular, que no solo excluye la relación sexual con los miembros de la propia familia sino que también exige el rechazo previo de la homosexualidad, organiza, defiende Rubin, las identidades de género. Y, en consecuencia, las identidades de género muestran huellas de los sistemas de parentesco que están al servicio de la heterosexualidad obligatoria. El género que se elabora a partir del parentesco supone asumir la identificación con un sexo y, asimismo, asumir que tu deseo sexual se tiene que dirigir hacia el otro sexo. En suma, el género implica dos aspectos: feminidad y masculinidad, por un lado, heterosexualidad, por el otro. Las identidades de género, las sexualidades, y las organizaciones de parentesco ahí implicadas, son productos históricos que a través del tiempo se han sedimentado adquiriendo el aspecto de naturales. Estas tesis de Rubin abren la posibilidad de ir más allá de las identidades de género establecidas mediante la intervención en los sistemas del parentesco.

La teoría queer reivindica a Rubin, por ello, como una de sus fuentes de influencia, porque, además, también Rubin cuestiona la categorización cerrada de mujeres y hombres como identidades naturales, fijas y radicalmente lejanas la una de la otra. Aunque, para mayor complejidad, tampoco podemos desconsiderar cómo el texto de Rubin asume en ciertos pasajes la defensa de un planteamiento igualitarista: «El sueño que me parece más atractivo es el de una sociedad andrógina y sin género (aunque no sin sexo), en que la anatomía sexual no tenga ninguna importancia para lo que uno es, lo que hace y con quién hace el amor ${ }^{26}$. Con anterioridad a la imposición de este

25. Ibíd., p. 83. Aquí Rubin, en nota 15, escribe: «Una psicóloga clínica, Charlotte Wolf (1971), ha llevado la teoría psicoanalítica de la feminidad a sus últimas consecuencias y ha propuesto que el lesbianismo es una respuesta sana a la socialización de las mujeres (...). La lesbiana indiscutiblemente ha estado y está en la vanguardia de la lucha por la igualdad de los sexos y por la liberación psíquica de las mujeres».

26. Ibíd., p. 85 .

Feminismo/s 15, junio 2010, pp. 33-54 
mecanismo cultural de sexo/género que transforma los sexos biológicos en géneros diferentes y jerarquizados, Rubin postula la existencia de individuos que encierran la totalidad de las posibilidades sexuales humanas. Dicho de otro modo, Rubin plantea que derrocada la heterosexualidad, se desvanecería el género.

En su texto posterior «Reflexionando sobre el sexo: notas para una teoría radical de la sexualidad ${ }^{27}$, Rubin dirigió sus esfuerzos hacia el análisis de las sexualidades con un enfoque distinto a su anterior atención al género. También este otro escrito, no obstante, es leído y citado positivamente por los estudios orientados hacia la teoría queer. En «Reflexionando sobre el sexo», Rubin analiza los sistemas concretos de poder que configuran las sexualidades, no solo las heterosexuales normativas sino que también afectan al lesbianismo y demás prácticas no convencionales, como el fetichismo, sadomasoquismo, travestismo, transexualidad o sexo en público. Investiga, y denuncia con fuerza, los mecanismos por los que unas sexualidades son consideradas normales, legítimas, buenas, saludables y otras como anormales, antinaturales, malas, pecaminosas. Separa aquí la sexualidad del género de modo que revisa la opresión ejercida sobre las sexualidades a partir de otros elementos, como la raza, la clase social, la regulación sexual. Rubin subraya aquí la necesidad de realizar una teoría autónoma sobre la sexualidad con la meta de llegar a desmantelar las opresivas jerarquías sexuales dominantes en la cultura occidental.

El contexto teórico que en sentido amplio denominamos feminismo de la diferencia sexual, por otra parte, tampoco encierra en su seno a pensadoras que coincidan nítidamente en todas sus apreciaciones feministas. Además, análisis concretos de algunas feministas de la diferencia sexual son reconocidos en su importancia feminista por autoras ajenas tanto al marco de la diferencia sexual como al de la igualdad. Porque en efecto, el feminismo se dice de múltiples maneras. Ágil y potente discurso crítico es el feminismo, que no se deja someter a estrechas y dualistas categorías.

Feminista postestructuralista, feminista queer, Judith Butler se pronuncia así:

Pero quiero advertir contra este tipo de lucha oposicional estricta. ¿Por qué algunas veces actuamos como si debiéramos renunciar totalmente a un planteamiento si este contiene algunas afirmaciones con las que no estamos de

27. RUBIN, Gayle. «Reflexionando sobre el sexo: notas para una teoría radical de la sexualidad». En C. S. Vance (comp.), Placer y peligro. Madrid, Talasa, 1989, pp. 113-190.

Feminismo/s 15, junio 2010, pp. 33-54 
acuerdo?, ¿qué modelo de pureza y violencia gobierna nuestro pensamiento en este caso ${ }^{28}$.

Con respecto a Luce Irigaray, aplicando su propia dinámica de reflexión abierta, antifundamentalista, atenta a la escucha-, afirma: «Creo que en su primera etapa elaboró una estrategia de lectura muy importante basada en la idea de mimesis (...). Y también pienso que incluso lingüísticamente había en sus primeros textos una capacidad de lectura que era muy crítica, hasta cierto punto deconstructiva ${ }^{29}$. Es, sin duda, con Rosi Braidotti con quien dialoga de un modo más fructífero. En este sentido comenta Butler: «En cuanto a Braidotti, creo que las dos estamos de acuerdo en que hay una crítica muy importante del sujeto y de la identidad que surge de un uso postestructuralista $»^{30}$. La productividad de la conversación entre ellas no arranca de la ausencia de divergencias entre sus ópticas de pensamiento sino que más bien viene incentivada precisamente por sus diferencias feministas. Butler es un ejemplo maestro de cómo es posible pensar por un camino antidogmático, estableciendo lazos y conexiones teóricas y prácticas:

Me parece que Braidotti y yo no estamos de acuerdo en nuestro modo de entender la categoría «mujeres». También creo que tenemos diferentes puntos de vista sobre la tecnología. Ella critica el uso de la tecnología como instrumento falocrático. Yo pienso que la tecnología está más abierta a diferentes usos y reutilizaciones. Desde mi punto de vista, su idea de solidaridad es en gran medida solidaridad entre mujeres, y cruzando las líneas entre lesbiana y heterosexual. De manera que, según Braidotti, la categoría «mujeres» nos uniría de un modo más fundamental, digamos, que nuestras preferencias sexuales. Por otra parte, estoy segura de que Braidotti y yo acudiríamos a las mismas manifestaciones, de que compartimos muchas opiniones políticas y de que apoyamos el trabajo de los/as estudiantes y las luchas institucionales de la otra. (...) Mi «línea compartida» no está tan firmemente trazada. Supongo que esto es también parte de mi idea de solidaridad, una solidaridad que atraviesa las diferencias. Y en la medida en que Braidotti sigue afirmando su solidaridad conmigo, quizá ella tenga una idea similar. Las dos hemos descrito nuestra relación como un «antagonismo cariñoso» ${ }^{31}$.

La potente problematización de las categorías de sexo, de género, de sexualidad que efectúa la obra de Butler, ha sido alimento en variadas producciones intelectuales. De algunas de ellas se ha ofrecido referencia más arriba.

28. ButLeR, Judith. «Entrevista con Judith Butler (por María Prado Ballarín y Elvira Burgos Díaz)». En E. Burgos Díaz, Qué cuenta como una vida. La pregunta por la libertad en Judith Butler. Madrid, Antonio Machado Libros, 2008, p. 405.

29. Ibíd., pp. 405-406.

30. Ibíd., p. 400.

31. Ibíd., pp. 400-401.

Feminismo/s 15, junio 2010, pp. 33-54 
Beauvoir inspira su consideración de la identidad de género como proceso siempre abierto e inacabado; Wittig le muestra una acerada crítica de la naturalidad del sexo, y de la dualidad sexual, así como del carácter opresivo del pensamiento heterosexual; Rubin le acerca a una reflexión donde el género está intimamente conectado con los sistemas de parentesco. Si el feminismo es una apuesta a favor de la vida, capaz de ampliar las posibilidades de vida en libertad, y un ejercicio comprometido con la subversión de las normas dualistas, excluyentes y violentas, no se aprecia qué fundamento podría tener la desconsideración sistemática de análisis feministas procedentes de perspectivas feministas distintas a la que configura la opción propia. Y tampoco se justificaría enarbolar un solo concepto como camino y como meta del feminismo, como aliento de la lucha; ya sea este concepto el de igualdad, el de justicia, el de diferencia, el de libertad:

Creo que la igualdad como ideal tiene una importancia considerable. (...) Se podría decir que las mujeres deberían ser iguales a los hombres, pero si esa proposición se convierte en la base de una política feminista, entonces no sólo hemos estabilizado la categoría «mujeres», sino que también hemos eliminado la posibilidad de un cuestionamiento crítico de esa categoría como parte de la política feminista. ¿Por qué la reivindicación de igualdad debería requerir que las feministas dejen de reflexionar acerca de la formación del sujeto, acerca de quién llega a ser una mujer y quién no, acerca del diferencial de poder que determina la constitución del género? Si parte de lo que el término feminismo significa es que las mujeres deberían ser libres para vivir vidas generizadas en modos que pueden muy bien impugnar la categoría «mujer», entonces no podemos conformarnos con las propuestas de un estricto igualitarismo. Necesitamos igualdad tanto como necesitamos libertad. Y si es esencial para el feminismo que las mujeres cuestionen las condiciones bajo las cuales tiene lugar el proceso de llegar a ser una mujer, entonces parece que las propuestas de la igualdad no pueden agotar los objetivos políticos del feminismo. Creo que necesitamos tener una constelación de términos normativos. La igualdad sería uno de ellos. La justicia, creo, es el segundo. Y pienso que no siempre es exactamente lo mismo que la igualdad. Finalmente, también la libertad es una categoría extremadamente importante $e^{32}$.

Se hace fuerte, este feminismo de Butler, en la tarea de la crítica y de la autocrítica. No persigue la búsqueda de espacios puros, no contaminados por el poder. El contexto social y cultural, que nos precede, que está ahí cuando venimos al mundo, es, justamente, el que nos posibilita la irrupción procesual, performativa, como sujetos inteligibles y recognoscibles. El mecanismo performativo de producción de subjetividad instaura identidades en cierto

32. Ibíd., pp. 399-400.

Feminismo/s 15, junio 2010, pp. 33-54 
modo siempre, constitutivamente, aunque en diferentes grados, inestables e incoherentes, en absoluto cerradas y permanentes desde el principio y hasta el final de nuestras vidas.

El rostro positivo de esta inestabilidad e incoherencia es que desde ahí se abre el espacio para la alteración, para la innovación transformadora de las constricciones que anidan en las normas de género y sexualidad. Las estrategias de resistencia son múltiples, móviles, dinámicas; suceden consciente y también inadvertidamente en ocasiones; y sus puntos de arranques son tanto individuales como colectivos. Ahora que, al no presuponerse un lugar completamente exterior al ámbito normativo, el trabajo de crítica y subversión se ha de organizar en el interior del marco del espacio social y cultural. Criticar las normas opresivas implica no solo la crítica de las instituciones y de los mecanismos sociales que sostienen y hacen circular las normas; implica, al mismo tiempo, una autocrítica en la que el sujeto se ve a sí mismo conmovido por dentro, porque aquello que parece ser solo externo, configura aquello que entendemos como lo interior y más personal; al mismo tiempo, la revuelta interior es una llamada al cambio del orden de lo social, a la modificación de las concepciones sociales del género y de la sexualidad: la separación entre exterior e interior queda trastocada, desplazada, invalidada. Cierto que ni el fracaso ni el éxito de nuestras acciones transgresoras están garantizados de antemano. Se trata de asumir un riesgo; pero en situación de riesgo de entrada ya estamos porque el riesgo es una dimensión de la vida misma.

Aunque el suyo es un feminismo que reivindica la interconexión entre feminismo y movimientos queer, entre la lucha contra el sexismo y la lucha contra el heterosexismo; un feminismo que se articula también oyendo las voces del activismo transgénero, transexual e intersexual; ello no le impide reconocer de un modo explícito que además se entiende a sí misma como una feminista en sentido clásico: "Todavía me considero una feminista clásica, porque lo cierto es que la mujer sigue sufriendo mucho más comparativamente, sobre todo si hablamos de temas de pobreza, analfabetismo y atención médica, de modo que ni siquiera a ese nivel básico ha finalizado la tarea del feminismo tradicional $\aleph^{33}$.

El feminismo de Butler no recurre a un sujeto previo del feminismo, a un sujeto fundacional que se postule como único punto de partida legítimo para la acción feminista. El sujeto del feminismo se va haciendo en las acciones feministas mismas, redefiniéndose constantemente. Su feminismo es una

33. BUTLER, Judith. «De literatura, mitos y estrellas. Entrevista con Judith Butler» (entrevista realizada por Patrícia Soley-Beltran). Minerva. Publicación cuatrimestral del Círculo de Bellas Artes, IV Época, 13 (2010), p. 45. 
incitación potente a sumar estrategias de acción antes que una prescripción de un camino único para el feminismo. Dicho está: Butler afirma el valor feminista de establecer lazos y conexiones entre teorías y movimientos, y asimismo se proclama feminista en sentido clásico.

Las denominaciones que el feminismo se ha ido otorgando en el devenir de su historia, se ha constatado, no pueden reducirse a solo dos marcos de intelección: igualdad o diferencia; y tampoco se debe dejar de subrayar cómo las obras feministas mismas, algunas al menos, exceden en sus formulaciones la pertenencia a una única categoría feminista. Reconociendo la vigencia y el claro interés de las problemáticas que continúan investigando las feministas autodenominadas de la igualdad o de la diferencia, no obstante, no se debe ni ignorar ni despreciar en su globalidad otras perspectivas de la reflexión feminista. Feminismo lesbiano, feminismo postestructuralista, feminismo queer: la importancia de sus análisis, si bien de modo breve y parcial, se ha pretendido mostrar en estas líneas. Y otras nuevas terminologías ${ }^{34}$ emergen en nuestros días y podrán emerger en el futuro para el feminismo, porque el feminismo es una teoría y un movimiento vivo, en devenir.

\section{Referencias bibliográficas}

BRAIDOtTI, Rosi. Sujetos nómades. Corporización y diferencia sexual en la teoría feminista contemporánea. Buenos Aires, Paidós, 2000.

Burgos DíAz, Elvira. Qué cuenta como una vida. La pregunta por la libertad en Judith Butler. Madrid, Antonio Machado Libros, 2008.

34. Elsa Dorlin en su texto Sexo, género y sexualidades. Introducción a la teoría feminista. Buenos Aires, Nueva Visión, 2009, habla de «praxis transfeministas» (p. 122). Se trata del feminismo que trabaja atendiendo la problemática transgénero; de un feminismo que se alimenta de los discursos y movimientos trans. Y en este contexto, Dorlin cita a Judith Butler. En el ámbito del Estado español, recientemente hemos podido observar cómo esta puesta en relación del feminismo con las políticas trans está teniendo una audiencia cada vez más importante, que merece ser tenida en cuenta también porque es un espacio conflictivo de debate que incentiva y enriquece la reflexión feminista. Me refiero en concreto a las Jornadas «Treinta años después. Aquí y ahora. Jornadas feministas estatales», organizadas en Granada por Asamblea de Mujeres de Granada «Mariana Pineda», Federación de Organizaciones Feministas del Estado Español, y que tuvieron lugar en diciembre de 2009. Con ocasión de estas Jornadas, se está difundiendo ampliamente, particularmente en la red y en el seno de diferentes colectivos feministas y LGTB, un Manifiesto para la insurrección transfeminista. Tendrá y tiene este manifiesto afirmaciones muy discutibles y que no tenemos por qué compartir, pero, en todo caso, es un signo de que el movimiento trans no puede ni debe permanecer al margen del feminismo.

Feminismo/s 15, junio 2010, pp. 33-54 
BUTLER, Judith. «De literatura, mitos y estrellas. Entrevista con Judith Butler» (entrevista realizada por Patrícia Soley-Beltran). Minerva. Publicación cuatrimestral del Círculo de Bellas Artes, IV Época, 13 (2010), pp. 43-46.

De Beauvoir, Simone. El segundo sexo. Buenos Aires, Ediciones Siglo Veinte, 1987.

Dorlin, Elsa. Sexo, género y sexualidades. Introducción a la teoría feminista. Buenos Aires, Nueva Visión, 2009.

HAINÄMAA, Sara. «¿Qué es ser mujer? Butler y Beauvoir sobre los fundamentos de la diferencia sexual». Mora, n. ${ }^{\circ} 4$ (1998), pp. 27-44.

RICH, Adrienne. «Heterosexualidad obligatoria y existencia lesbiana». En A. Rich, Sangre, pan y poesía. Barcelona, Icaria, 200, pp. 41-86.

RUBIN, Gayle. «El tráfico de mujeres: notas sobre la «economía política» del sexo». En M. Lamas (compiladora), El género: La construcción cultural de la diferencia sexual. México, Universidad Nacional Autónoma de México-PUEG, 2000, pp. 35-96.

RUBIN, Gayle. «Reflexionando sobre el sexo: notas para una teoría radical de la sexualidad». En C. S. Vance (comp.), Placer y peligro. Madrid, Talasa, 1989, pp. 113-190.

SUÁREZ BRIONES, Beatriz. «De cómo la teoría lesbiana modificó a la teoría feminista (y viceversa)». En M. Bengoechea y M. Morales (editoras), (Trans)formaciones de las sexualidades y el género. Alcalá de Henares, Universidad de Alcalá. Servicio de Publicaciones, 2001, pp. 55-67.

SuÁREZ BRIONES, Beatriz. «Desleal a la civilización: la teoría (literaria) feminista lesbiana». En X. M. Buxán (ed.), Conciencia de un singular deseo. Barcelona, Laertes, 1997, pp. 257-279.

SuÁrez Briones, Beatriz. Sextualidades: teorías literarias feministas, Alcalá de Henares, Excelentísimo Ayuntamiento de Alcalá de Henares. Concejalía de la Mujer. Centro Asesor de la Mujer, 2002.

Wittig, Monique y Sande Zeig. Borrador para un diccionario de las amantes. Barcelona, Editorial Lumen, 1981.

Wittig, Monique. El cuerpo lesbiano. Valencia, Pre-Textos, 1977.

Wittig, Monique. El pensamiento heterosexual y otros ensayos. Madrid, Editorial Egales. 2006.

WitTig, Monique. Las guerrilleras. Barcelona, Seix Barral, 1971. 